\title{
Predictors of intentions to stop smoking early in prenatal care
}

\author{
Daniel H Ershoff, Laura J Solomon, Patricia Dolan-Mullen
}

\begin{abstract}
Objective-To determine baseline variables associated with low intentions of stopping smoking early in pregnancy.

Design-Cross sectional survey.

Participants-Pregnant smokers pooled across seven Smoke-Free Families trials $(\mathbf{n}=1314)$.

Results-36\% of pregnant smokers had low intentions of stopping smoking within the next 30 days. In contrast to pregnant smokers with higher intentions of quitting, pregnant smokers with low intentions were less confident in their ability to quit, less likely to have private health insurance, and less likely to agree that smoking harms the unborn child. They were more likely to smoke heavily, more likely to have fewer years of education, and more likely to have friends and family members who smoke. Conclusions-Three options to smoking cessation assistance are proposed for pregnant smokers with low intentions of quitting: targeting, triage, and tailoring. Further research is needed to determine which approach is most appropriate.

(Tobacco Control 2000;9(Suppl III):iii41-iii45)
\end{abstract}

Keywords: smoking cessation; pregnancy; intentions

Smoking cessation programs for pregnant women in the USA have reported smaller effects in more recent trials compared to studies conducted in the early $1980 \mathrm{~s}^{1-3}$ One hypothesis is that more of the women who smoke before pregnancy stop as soon as they recognise the pregnancy, leaving less motivated, more addicted smokers still smoking. "Spontaneous quitters" are typically light smokers who are well educated, have less saturated smoking networks, and more recognition of the risks of smoking during pregnancy. Evidence that spontaneous cessation among pregnant women has increased is not clear, however. Secker-Walker and colleagues observed a steady proportion of spontaneous quitters $(23 \%$ and $24 \%$, respectively) across time in their studies of low income, pregnant, white women in Vermont. ${ }^{4}$ Ershoff and Quinn found a larger proportion of spontaneous quitters in the late $1990 \mathrm{~s}(60 \%)$ compared to the mid 1980s (40\%) among pregnant women receiving care from health maintenance organisations (HMOs). ${ }^{36}$ Windsor and colleagues reported a spontaneous quit rate of $15 \%$ among low income African American pregnant women in the $1980 \mathrm{~s},{ }^{78}$ as contrasted with a rate of approximately $22 \%$ in their current study among Medicaid recipients in Alabama ( $\mathrm{R}$ Windsor, personal communication, September 1999).
Additional evidence from the Birmingham trials that the profile of smokers presenting for prenatal care has changed during the past decade is the finding that the mean cotinine concentrations at entry into prenatal care have increased approximately $80 \mathrm{ng} / \mathrm{ml}$ ( $\mathrm{R}$ Windsor, personal communication, September 1999). Data from several studies have revealed that cognitive behavioural prenatal cessation programs have had minimal impact on the subset of more addicted smokers. ${ }^{8-12}$

A related hypothesis to account for the diminished impact of cessation programs in recent trials of pregnant women suggests that a sizeable proportion of pregnant smokers who do not quit spontaneously on their own when they find out about their pregnancy may have low readiness to change. Results from several smoking cessation trials with pregnant women reveal the lowest quit rates during pregnancy among these women. ${ }^{313}$ This group of smokers warrants further attention if we are to understand the outcomes of smoking cessation trials with pregnant women and push the modest gains in cessation to higher levels.

This paper uses cross sectional data pooled across seven smoking cessation trials comprised of pregnant women who are starting prenatal care or the WIC program (Women, Infants, and Children Supplemental Feeding Program) with the objective of contrasting smokers with low intentions of quitting within the next 30 days with their counterparts who have higher intentions of quitting within the same timeframe.

\section{Methods}

SETTING AND DATA COLLECTION

Data for the analysis were obtained from the Smoke-Free Families projects that focused on cessation during the prenatal period. Further details regarding the individual study sites are available elsewhere ${ }^{3}$ and in this issue. ${ }^{14-18}$ The sites encompassed diverse populations, including a large prepaid group practice with a predominantly middle class, privately insured population, a university teaching hospital and WIC/public health maternity clinics serving Medicaid beneficiaries and uninsured women. Between February 1996 and November 1997, baseline questionnaires were administered to 1528 pregnant smokers who were $<26$ weeks' gestation and gave consent for one of the trials. The current analysis is based on the 1372 cases in which women reported at baseline that: (a) they were current smokers; (b) they had smoked more than one cigarette in the previous seven days; and (c) they responded to the item assessing their intention to quit smoking within the next 30 days. 
With the exception of two sites where data were obtained from telephone ${ }^{3}$ or face-to-face interviews, ${ }^{18}$ baseline data were from self administered questionnaires. In addition to other constructs that may have been included, the baseline questions at each site included approximately 25 "core items". The timing of the administration of the baseline instrument relative to a woman's first visit for prenatal medical care varied by site. At sites where the location of the research study and the obstetric care were identical, the baseline instrument was usually administered at the first visit. Conversely, in sites when subjects were impaneled at WIC clinics or other non-medical settings, the baseline was often administered several weeks after the first prenatal visit. The baseline assessment was administered, on average, at 12.9 weeks gestation (57.5\% in the first trimester).

MEASURES

Two "core items" assessed behavioural intentions regarding cessation during pregnancy. The first item assessed whether the woman was seriously thinking about quitting smoking completely during the pregnancy. The subset of women who indicated that they were serious were next asked if they were planning to quit smoking completely within the next 30 days. Approximately $80 \% \quad(1115 / 1372)$ of women reported that they were seriously thinking about quitting during pregnancy, and $64 \%(881 / 1372)$ indicated that they intended to quit within the next 30 days.

Given the known social desirability of response associated with asking pregnant women whether they intend to quit during pregnancy, especially in a clinical setting, we felt the more restrictive 30 day measure would provide a more valid assessment of pregnant smokers' behavioural intentions with respect to cessation. Also, we regarded this timeframe as more consistent with the health benefits of stopping smoking in pregnancy - the earlier the better. Thus, the dependent variable for the study classified pregnant smokers into the 36\% ( $\mathrm{n}=491$ ) who did not intend to quit within the next 30 days (low intentions), and the remaining $64 \% \quad(\mathrm{n}=881)$ who provided an affirmative response regarding cessation intentions within this timeframe (high intentions).

Substantial variation was observed across the seven sites in the percentage of smokers with low intentions, ranging from lows of $15 \%$ at Kaiser Permanente ${ }^{3}$ and $26 \%$ at Oregon ${ }^{15}$ to a high of $57 \%$ at Dana Farber. ${ }^{14}$ In the four other sites, the percentage of women classified as low intention ranged from $42-48 \%$.

Data from two of the trials ${ }^{318}$ were used to check prospectively the relationship between baseline behavioral intentions with end-ofpregnancy biochemically confirmed, seven day point prevalence cessation. A strong association was detected, with only $9 \%$ of women with low intentions to quit within 30 days of baseline classified as biochemically confirmed quitters $(9 / 101)$ as contrasted with $23 \%(80 / 351)$ of women with high intentions. The promising predictive validity of this behavioural intention item prompted the current analysis which sought to identify multivariate predictors of high versus low intentions to quit smoking.

The baseline core measures included: (1) sociodemographic characteristics (age, education, race/ethnicity, health insurance status); (2) level of addiction (number of cigarettes and minutes to first cigarette in the morning) before pregnancy and currently; (3) smoking history (prior quit attempts and age of smoking initiation); (4) beliefs (motivation to quit and motivation to continue smoking during pregnancy and belief in the impact of smoking on the health of the mother and the fetus); (5) confidence in their ability to quit in the next 30 days; (6) social networks and social support (number of friends and family who smoke, number of smokers in the household, and expected support from family, friends and co-workers if a quit attempt were made); and (7) mental health (lifetime episode of feeling "down" or being "depressed" for more than two weeks, and feeling "downhearted and blue" during the previous month from the Mental Health Index-5). ${ }^{19}$ The response categories for the belief, social support, and confidence items, respectively, were "none/not at all" (coded 1), "a little" (coded 2), "some" (coded 3), and "a lot/very" (coded 4). The response categories for depression in the last month (for this analysis) ranged from "none of the time" (coded 1) to "all of the time" (coded 4). The item assessing how many friends and family members smoked also had four response categories, from "none" (coded 1) to "most" (coded 4).

STATISTICAL ANALYSIS

Subjects classified into the categories of intending and not intending to quit within the next 30 days were compared on baseline measures using $\chi^{2}$ for categorical variables and the $t$ test for continuous variables. Items with four response categories were treated as continuous variables in both the univariate and multivariate analyses. An $\alpha$ of $<0.05$ was the criterion for significance. Forward, stepwise logistic regression analysis was used to assess the combined influence of baseline variables in differentiating women with low and high intentions of quitting within the next 30 days. The odds ratio (and 95\% confidence intervals) was used to measure the degree of association between the significant multivariate predictors and behavioral intention. All statistical analyses were conducted using SPSS for Windows, Version 7.5.

\section{Results}

UNIVARIATE COMPARISONS

Overall, the sample can be characterised as being in their mid-20s and having had an average of 12 years of education; three quarters were white, $41 \%$ were primipara, and $41 \%$ had private health insurance (table 1). With the exception of age, significant group differences were detected for all demographic variables. As contrasted with women with low intentions, women with high intentions had more years of education, were more likely to be Hispanic, primiparous, and covered by private health insurance; they were also more likely to have completed the baseline survey within the first trimester of their pregnancy. 
Table 1 Baseline variables by intention to quit within 30 days

\begin{tabular}{|c|c|c|c|}
\hline & $\begin{array}{l}\text { Low intention of quitting } \\
\text { within } 30 \text { days }(n=491)\end{array}$ & $\begin{array}{l}\text { High intention of quitting } \\
\text { within } 30 \text { days }(n=881)\end{array}$ & Total $(n=1372)$ \\
\hline \multicolumn{4}{|l|}{ Demographics } \\
\hline Mean (SD) age (years) & $25.3(6.5)$ & $25.8(6.5)$ & 25.6 (6.5) NS \\
\hline Mean (SD) education (years) & $11.5(1.9)$ & $12.1(1.9)$ & $11.9(2.0)^{\star \star}$ \\
\hline \multicolumn{4}{|l|}{ Race $(\%)$} \\
\hline White & 80.2 & 71.7 & $74.8^{\star \star}$ \\
\hline African American & 10.6 & 12.6 & 11.9 \\
\hline Hispanic & 4.5 & 9.4 & 7.7 \\
\hline Other & 4.7 & 6.3 & 5.6 \\
\hline Parity (\%primipara) & 35.7 & 43.9 & $42.1^{\star}$ \\
\hline Insurance status (\% private) & 26.5 & 48.8 & $40.6^{\star \star}$ \\
\hline Weeks pregnant at baseline (\% first trimester) & 53.5 & 62.4 & $59.2^{\star \star}$ \\
\hline \multicolumn{4}{|l|}{ Smoking history } \\
\hline Prepregnancy cigs/day (mean) (SD) & $21.8(11.1)$ & $17.6(9.3)$ & $19.1(10.2)^{\star \star}$ \\
\hline Baseline (past 7 days) cigs/day (mean) (SD) & $12.8(9.0)$ & $7.7(7.3)$ & $9.5(8.4) \star \star$ \\
\hline Minutes to 1 st cig (prepregnancy) $(\%<30$ minutes $)$ & 72.4 & 58.7 & $63.6^{\star \star}$ \\
\hline Minutes to 1 st cig (baseline) $(\%<30$ minutes $)$ & 53.4 & 32.4 & $40.0^{\star \star}$ \\
\hline Prepregnancy quit attempts (mean) (SD) & $1.7(5.4)$ & $2.4(6.8)$ & $2.1(6.3)^{\star \star}$ \\
\hline Pregnancy quit attempts $(\% 1+)$ & 32.2 & 61.3 & $50.9^{\star}$ \\
\hline Age began smoking (mean) (SD) & $14.7(5.0)$ & $15.6(3.6)$ & $15.3(4.2)^{\star \star}$ \\
\hline \multicolumn{4}{|l|}{ Beliefs, attitudes } \\
\hline \multicolumn{4}{|l|}{ Want to stop smoking } \\
\hline Mean (SD) & $3.0(0.88)$ & $3.8(0.49)$ & $3.5(0.75)^{\star \star}$ \\
\hline “A lot” (\%) & 33.7 & 81.3 & 64.2 \\
\hline \multicolumn{4}{|l|}{ Want to keep smoking } \\
\hline Mean (SD) & $2.3(0.90)$ & $1.7(0.83)$ & $1.9(0.91)^{\star \star}$ \\
\hline "A lot" (\%) & 9.6 & 4.0 & 6.0 \\
\hline \multicolumn{4}{|l|}{ Smoking harms unborn child } \\
\hline Mean (SD) & $3.3(0.78)$ & $3.6(0.67)$ & $3.5(0.72)^{\star \star}$ \\
\hline "A lot" (\%) & 47.6 & 71.0 & 62.3 \\
\hline \multicolumn{4}{|l|}{ Smoking harms mothers' health } \\
\hline Mean (SD) & $3.5(0.66)$ & $3.8(0.52)$ & $3.7(0.58)^{\star \star}$ \\
\hline "A lot" (\%) & 61.9 & 80.7 & 74.0 \\
\hline \multicolumn{4}{|l|}{ Confidence in ability to quit in next 30 days } \\
\hline Mean (SD) & $2.4(0.97)$ & $3.1(0.88)$ & $2.7(1.0)^{\star \star}$ \\
\hline "Very" (\%) & 9.5 & 32.7 & 24.6 \\
\hline \multicolumn{4}{|l|}{ Network/support } \\
\hline \multicolumn{4}{|l|}{ Number of friends and family who smoke } \\
\hline Mean $(\mathrm{SD})$ & $3.3(0.83)$ & $3.0(0.95)$ & $3.1(0.92)^{\star \star}$ \\
\hline "Most" (\%) & 50.3 & 42.3 & 45.2 \\
\hline \multicolumn{4}{|l|}{ Number of household smokers } \\
\hline Mean (SD) & $1.2(1.4)$ & $1.1(1.4)$ & $1.2(1.4) \mathrm{NS}$ \\
\hline "1+ smoker" (\%) & 70.9 & 67.8 & 68.9 \\
\hline \multicolumn{4}{|l|}{ Anticipated support in quitting } \\
\hline Mean (SD) & $3.2(0.97)$ & $3.6(0.79)$ & $3.4(0.88)^{\star \star}$ \\
\hline “A lot” (\%) & 54.0 & 72.6 & 66.0 \\
\hline \multicolumn{4}{|l|}{ Mental health } \\
\hline Lifetime feeling of depression ("yes" (\%)) & 43.5 & 35.3 & 35.1 \\
\hline \multicolumn{4}{|l|}{ Past month felt down and blue } \\
\hline Mean (SD) & $2.3(0.82)$ & $2.2(0.78)$ & $2.2(0.79) \mathrm{NS}$ \\
\hline "All" (\%) & 10.2 & 7.4 & 8.4 \\
\hline
\end{tabular}

${ }^{\star} \mathrm{p}<0.05 ;{ }^{\star \star} \mathrm{p}<0.01$

Before this pregnancy, the sample had smoked nearly a pack a day, which by the time of the administration of the baseline had been reduced by half. Similarly, nearly two thirds of the sample reported having smoked their first cigarette within 30 minutes of waking before pregnancy, down to $40 \%$ at baseline. Subjects had begun smoking regularly at age 15 , reported two quit attempts before the pregnancy, with half reporting a quit of at least 24 hours since having learned of this pregnancy. Significant group differences were detected for all of these items. The subgroup of women with high intentions were lighter smokers (both before pregnancy and at baseline) and appeared less addicted to nicotine at both time periods. Women with high intentions reported more quit attempts both before and during this pregnancy, and, on average, had started smoking on a regular basis approximately a year after women with low intentions.

Nearly two thirds of the sample reported that they wanted to stop smoking "a lot" versus $6 \%$ who said they wanted to continue to smoke "a lot". Nearly two thirds of the sample endorsed the statement that cigarette smoking could harm the health of their unborn child "a lot" and nearly three quarters felt that cigarette smoking could harm their own health during pregnancy. One quarter were "very confident" in their ability to quit smoking in the next month. Significant differences were observed between the high and low intention groups on each of these five items. The high intention subgroup endorsed higher motivation to quit, stronger belief in the harmful effects of smoking on their own health and that of their fetus, and more confidence in their ability to quit during pregnancy.

Nearly half of the study participants reported that "most" of their friends and family that they see regularly were smokers. Nevertheless, two thirds anticipated "a lot" of support if they tried to quit. As contrasted with women reporting low intentions, those with high intentions reported that fewer of their friends smoked, and they anticipated receiving more support. No group differences were found for the presence of another smoker in the household, with approximately two thirds of subjects in both groups reporting that they 
Table 2 Logistic regression analysis predicting intentions to quit smoking within 30 days of administration of baseline questionnaire

\begin{tabular}{lrrll}
\hline Variable & Coefficient & Wald & Significance & Odds ratio (95\% CI) \\
\hline Confidence in ability to quit (a) & 0.900 & 142 & 0.000 & $2.46(2.12$ to 2.85) \\
Private insurance coverage (b) & 0.725 & 23 & 0.000 & $2.01(1.53$ to 2.77) \\
Cigarettes/day at baseline (c) & -0.041 & 22 & 0.000 & $0.96(0.94$ to 0.97) \\
Belief smoking can harm baby (a) & 0.440 & 22 & 0.000 & $1.53(1.29$ to 1.86$)$ \\
Years of education (d) & 0.104 & 7 & 0.005 & $1.11(1.03$ to 1.19$)$ \\
Number of friends who smoke (a) & 0.154 & 5 & 0.050 & $1.16(1.00$ to 1.36$)$
\end{tabular}

(a) Odds associated with a one unit increase on an item with four categories.

(b) Odds associated with change in category from no insurance coverage to coverage.

(c) Odds associated with consumption of one additional cigarette/day.

(d) Odds associated with one additional year of education.

CI, confidence interval. comparing the odds ratios. The inclusion of these three items increased the Nagelkerke $\mathrm{R}^{2}$ to 0.34 . Finally, educational level, and an item assessing smoking social networks, were significant predictors within the context of the other four variables, although the inclusion of these two measures increased the Nagelkerke $\mathrm{R}^{2}$ only slightly to 0.35 .

\section{Discussion}

Our findings indicate that several baseline characteristics differentiate pregnant smokers with low intentions to stop smoking from those with high intentions. In the multivariate analysis predicting intentions at baseline, we found that women with low intentions were less confident in their ability to quit smoking, less likely to have private health insurance, and less convinced that smoking harms the unborn child. Additionally, they smoked more cigarettes per day, had fewer years of education, and were more likely to have friends and family members who smoke. These variables associated with low intentions to quit smoking early in prenatal care reflect smoking beliefs, addiction, demographic characteristics, and the social environment. Thus, a combination of factors conspires to produce low intentions to quit smoking early in prenatal care.

Prior studies of pregnant smokers have observed a significantly lower quit rate at the end of pregnancy among women with low intentions to quit during their pregnancy compared to smokers with higher intentions to quit. Solomon and colleagues ${ }^{20}$ found that pregnant smokers with low intentions to quit who received physician smoking cessation advice plus counselling from an obstetric nurse at their first prenatal visit were more likely to make positive changes in their smoking by their second prenatal visit compared to pregnant smokers with low intentions who received physician advice alone. The experimental condition had no effect on end-of-pregnancy quit rates among smokers with low intentions, however, and findings from two studies among the Smoke-Free Families projects reported in this supplement observed similar low levels of quitting (less than 10\%) among pregnant smokers with low intentions at baseline. ${ }^{3} 18$

Because we are least successful in our efforts to help pregnant women with low intentions of stopping smoking, and because over a third of pregnant women who smoke have low intentions of quitting early in prenatal care, it is useful to consider the options for smoking cessation assistance with this group.

We know from the broader literature on processes of change that few change strategies are routinely employed by persons with low intentions of quitting. ${ }^{21-23}$ We also know from our own findings that these women face attitudinal, addiction related, and environmental barriers to change. Thus, one option is to invest considerable resources in helping these women by simultaneously addressing each of these barriers. This might mean, for example, employing motivational interviewing to affect beliefs about smoking and confidence in quitting, ${ }^{24}{ }^{25}$ considering the early use of nicotine replacement or 
other pharmacologic agents to overcome the addiction itself, ${ }^{26}$ and supplying ongoing support, problem solving, and reinforcement throughout the pregnancy to counter the adverse influences of a smoking environment. ${ }^{28}$ This option could be characterised as targeting smokers identified as having low intentions and providing maximal intervention to try to change their smoking behaviour.

An alternative approach might recognise that health care providers have a finite amount of time and resources to invest in helping pregnant women stop smoking, and acknowledge that we are least successful in helping those with low intentions. Therefore, we might choose to invest more resources in those pregnant smokers with whom we are most successful, and provide minimal assistance to those with poor prognostic profiles. This approach, which might be called triage, limits the effort spent with smokers having low intentions of quitting and places higher priority on assisting more promising clients.

A third option might fall between the other two. This approach, which could be considered tailoring, would recognise the barriers to quitting faced by pregnant smokers with low quitting intentions, acknowledge that the goal of quitting smoking during pregnancy may be unrealistic, and seek to help these women with a harm reduction approach. Such a strategy might set substantial reduction in cigarettes per day or in cotinine or carbon monoxide concentration as the goal during pregnancy. Findings from several studies indicate that substantial reductions in smoking (to as low as five cigarettes per day) have a positive impact on infant birth weight ${ }^{29}{ }^{30}$. Thus, this more proximal goal of substantial reduction during pregnancy could achieve some health benefit and may be more palatable to smokers with low intentions than the goal of quitting. Because the goal of this approach would be individualized, it could be considered a form of tailoring. ${ }^{31}$

Targeting, triaging, and tailoring represent three clinical approaches to the management of smoking among pregnant women with low intentions of quitting. Controlled outcome trials that include a cost effectiveness analysis may be the only way to sort out which approach makes the most sense for this segment of the population.

The authors wish to acknowledge the support of the Robert Wood Johnson Foundation's Smoke Free Families Program and recognise the investigators and collaborating organisation of the seven projects whose data are used here: Karen $M$ Emmons, Dana Farber Cancer Institute; Douglas W Hoffman and Judith E Frank, Dartmouth-Hitchcock Medical Center; Susan L Prows and Rebecca J Donatelle, Oregon State University: Walter I Scott, Creighton University; and the Uuther sity; Walter J Scott, Creighton University; and the authors, Ershoff, Southern California Kaiser-Permanente; Mullen, University of Texas-Houston; and Solomon, University of Vermichard Windsor, Joyce Atkinson, and Jinrong Hou of the National Program Office for their insightful comments and technical assistance.

1 Dolan-Mullen P, Ramirez G, Groff JY. A meta-analysis of randomized trials of prenatal smoking cessation intervenrandomized trials of prenatal smoking cessatio
tions. Am 7 Obstet Gynecol 1994;171:1328-34.

2 Mullen PD, Ramirez G. Efforts to reduce tobacco use among women: pregnant women and mothers. In: US Public Health Service: Office on Smoking and Health. The health consequences of smoking for women. A report of the Surgeon General. Rockville, Maryland: US Department of Health and Human Services. In press.
3 Ershoff DH, Quinn VP, Boyd NR, Stern J, Gregory M, Wirtschafter D. The Kaiser Permanente prenatal smoking cessation trial: when more isn't better, what is enough? Am J Prev Med 1999;17:161-8.

4 Secker-Walker RH, Solomon LJ, Flynn BS, et al. Smoking relapse prevention counseling during prenatal and early postnatal care. Am f Prev Med 1995;11:86-93.

5 Secker-Walker RH, Solomon LJ, Flynn BS, Skelly JM, Mead PB. Smoking relapse prevention during pregnancy: a trial of coordinated advice from physicians an
individual counseling. Am $\mathcal{F}$ Prev Med 1998;15:25-31.

6 Quinn VP, Mullen PD, Ershoff DH. Women who stop smoking spontaneously prior to prenatal care and predictors of relapse before delivery. Addictive Behaviors 1991; 6:153-60.

7 Windsor RA, Cutter G, Morris J, Reese J, et al. The effectiveness of smoking cessation methods for smokers in public health maternity clinics: a randomized trial. Am $\mathcal{F}$ Public Health 1985;75:1389-92.

8 Windsor RA, Lowe JB, Perkins LL, et al. Health education for pregnant smokers: its behavioral impact and cost benefit. Am F Public Health 1993;83:201-6.

9 Ershoff DH, Mullen PD, Quinn VP. A randomized trial of a serialized self-help smoking cessation program for pregnant women in an HMO. Am F Public Health 1989;79:182-7.

10 O'Connor AM, Davies BL, Dulberg CS, et al. Effectiveness of a pregnancy smoking cessation program. F Obstet Gyneof a pregnancy smoking cessation
col Neonatal Nurs 1992;21:385-92.

11 Woodby LL, Windsor RA, Snyder SW, Kohler CL, DiClemente CC. Predictors of smoking cessation during DiClemente CC. Predictors of smoking
pregnancy. Addiction 1999;94:283-92.

12 Secker-Walker RH, Solomon LJ, Flynn BS, et al. Individualized smoking cessation counseling during prenatal and early postnatal care. Am $\mathcal{F}$ Obstet Gynecol 1994;171:134755.

13 Secker-Walker RH, Solomon LJ, Flynn BS, Skelly JM, Mead PB. Reducing smoking during pregnancy and postpartum: physician's advice supported by individual counseling. Prev Med 1998;27:422-30.

14 Emmons KM, Sorensen G, Klar N, et al. Healthy baby second-hand smoke study: project brief. Tobacco Control 2000;9(suppl III):iii58-9.

15 Donatelle RJ, Prows SL, Champeau D, Hudson LD. Randomised controlled trial using social support and finanical incentives for high risk pregnant smokers: significant other supporter (SOS) program. Tobacco Control 2000;9(suppl III):iii67-9.

16 Scott WJ, McIlvain HE. Interactive software: an educational/behavioural approach to smoking cessation for pregnant women and their families.9(suppl III):56-7.

17 Dolan-Mullen P, DiClemente CC, Velasquez MM, et al. Enhanced prenatal case management for low income smokers. Tobacco Control 2000;9(suppl III):iii75-7.

18 Solomon LJ, Secker-Walker RH, Flynn BS, Skelly JM, Capeless EL. Proactive telephone peer support to help pregnant women stop smoking. Tobacco Control 2000; pregnant women
9(suppl III): $72-4$.

19 Berwick DM, Murphy JM, Goldman PA, Ware JE, Barsky AJ, Weinstein MC. Performance of a five-item mental health screening test. Medical Care 1991;29:169-76.

20 Solomon LJ, Secker-Walker RH, Skelly JM, Flynn BS. Stages of change in smoking during pregnancy in low-income women. F Behav Med 1996;19:333-44.

21 DiClemente CC, Prochaska JO, Fairhurst SK, Velicer WF, Velasquez MM, Rossi JS. The process of smoking cessation: an analysis of precontemplation, contemplation, and preparation stages of change. $\mathcal{F}$ Consult Clin Psychol 1991;59:295-304.

22 Fava JL, Velicer WF, Prochaska JO. Applying the transtheoretical model to a representative sample of smokers. Addictive Behaviors 1995;20:189-203.

23 Herzog TA, Abrams DB, Emmons KM, Linnan LA, Shadel WG. Do processes of change predict smoking stage movements? A prospective analysis of the transtheoretical model. Health Psychol 1999;18:369-72.

24 Miller WR, Rollnick S. Motivational interviewing: preparing people to change addictive behavior. New York: Guilford Press, 1991.

25 Velasquez MM, Hecht J, Quinn VP, Emmons K, DiClemente CC, Dolan-Mullen P. Application of motivational interviewing to prenatal smoking cessation: training and implementation issues.Tobacco Control 2000;9(suppl III):iii36-40.

26 Benowitz NL. Nicotine replacment therapy during pregnancy. $\mathcal{F} A M A$ 1991;266:3174-7.

27 Anon. Workshop on the use of pharmacotherapies for smoking cessation in pregnancy. National Institute for Child Health and Human Development and the Smoke-Free Families Program. Rockville, Maryland, May 19, 1999.

28 Smoking Cessation Clinical Practice Guideline Panel and Staff. The Agency for Health Care Policy and Research smoking cessation clinical practice guideline. $7 A M A 1996$; 275:1270-80.

29 Secker-Walker RH, Vacek PM, Flynn BS, Mead P. Estimated gains in birth weight associated with reductions in smoking during pregnancy. F Reprod Med 1998;43:967-74.

$30 \mathrm{Li} \mathrm{CQ}$, Windsor RA, Perkins L, Goldenberg RL, Lowe JB. The impact on infant birth weight and gestational age of cotinine-validated smoking reduction during pregnancy. FAMA 1993;269:1519-24.

31 Kreuter MW, Skinner CS. Tailoring: what's in a name. Health Education Research 2000;15:1-4. 